Article

\title{
How May Public Transport Influence the Practice of Everyday Life among Younger and Older People and How May Their Practices Influence Public Transport?
}

\author{
Lena Levin $(\mathbb{D}$ \\ Mobility, Actors, Planning Processes, The Swedish National Road and Transport Research Institute (VTI), \\ SE-581 95 Linköping, Sweden; lena.levin@vti.se; Tel.: +46-13-204224
}

Received: 21 December 2018; Accepted: 8 March 2019; Published: 13 March 2019

check for updates

\begin{abstract}
This paper examines public transport use through the lens of practice to understand the perspectives of two categories of public transport users: Younger and older people. In taking this approach, we assume that the forms of mobility in a society are dependent on citizens' everyday practices and on the structures of the cities, landscapes, etc. Transport needs and accessibility may vary depending on contexts (i.e., where and how we live) and on the various resources of groups of citizens. Results indicated that younger people are repeatedly referred to public transport to meet their mobility needs, while older people are more often car-dependent. Local variations, among both younger and older people, indicate higher confidence in public transport in big and medium-sized cities and a greater desire for car ownership in small cities. For the transition to sustainable mobility, e.g., public transport, transport associations and local governments should be responsive to the practice of everyday life among citizens: e.g., younger people's leisure activities in afternoons and weekends, and older people's wish for accessible transport service outside the dominant flow of passengers and their daily commuting practice. The data come from Sweden, specifically from focus groups with teenagers aged 14-16 years and retired people aged 63-97 years.
\end{abstract}

Keywords: public transport; mobility; practice; travellers; older people; younger people; independence

\section{Introduction}

Transport mobility is a field of practice that needs to be transformed in conjunction with climate change and sustainability concerns in Europe, where there is a desire to demonstrate global leadership in reducing environmental impacts. Innovation and technological research are certainly driving forces of smarter and cleaner mobility, but there will still be a need for transition in the everyday practices of citizens (European Environment Agency 2017, 2018). For example, urban programmes for reducing automobility and promoting transition to public transport mobility will intervene in people's lives and wellbeing. Technological solutions may not be enough, and new challenges to everyday mobility and restrictions on existing transport infrastructure will become more noticeable as problems of, for example, global warming, pollution, and noise, intensify. These problems must be addressed first and primarily in urban environments, but challenges will also face those living in suburban and rural areas (cf. Mattioli 2014).

In this study, we used focus group discussion of public transport among 'older' retired people and 'younger' people comprising teenagers in secondary school. We brought together data from previous studies to compare how these two groups express their preferences and experiences regarding the public transport system and the place of public transport in their 'everyday mobility' practice.

Transport infrastructure accounts for a large proportion of environmental impact, especially as it affects health and social life. Transport also has a positive impact on the economy, social life, 
and provision of healthcare and services. Transport needs and accessibility may vary depending on contexts, e.g., where and how we live and the differing resources of groups of citizens. At the same time, as there are divergent views of what change will mean for different groups of citizens, this article considers two age groups, teenagers and retired people. Data come from two previous case studies completed over several years during the past decade. The aims of these studies were to examine the two age groups' mobility needs, access to, and experiences of public transport, and to consider how public transport compares with other transport modes. These matters merit study in light of the ongoing mode transition in many European countries (i.e., decreasing automobility in favour of more public transport), which may influence the practices of younger and older people as well as their wellbeing. The case studies were conducted in Sweden, which is a limitation for conducting an analysis to be considered valid for Europe as a whole but nevertheless gives an indication that knowledge of different age groups should be included more systematically when planning for comprehensive change in the transport sector. There have so far been few qualitative user-centred studies focussing on these two age groups together (see, e.g., Broome et al. 2010; Jones et al. 2013). The studied groups do not comprise ordinary commuters (i.e., adults travelling to work) and may need solutions other than mainstream public transport to meet their transport needs now and in the future.

\subsection{Aim}

This article examines two categories of public transport users at the margins of public transport planning, problematising the discussion of their everyday mobility through invoking the concept of practice. Specifically, we chose younger and older people because their experiences are of great interest for modern societies in attempts to increase public transport's share of total transport provision. The following questions guide the analysis: How do mobility experiences appear in focus groups among younger and older people? What patterns are discernible in these groups? Are there any similarities that could be pertinent to meeting both younger and older people's mobility needs?

\subsection{Structure of the Article}

After this introduction, Section 2 describes the starting points of the present study, considering recurrent concepts (Section 2.1) and contexts (Section 2.2), and links to previous research into older and younger people's everyday mobility (Sections 2.3 and 2.4). Materials and Methods (Section 3), Results (Section 4), and finally Discussion (Section 5) complete the paper.

\section{Theoretical and Contextual Starting Points}

\subsection{Concepts}

The starting point here is the European goal of ensuring the free movement of citizens as a fundamental principle of the functioning of the European Union, and mobility as a fundamental right (cf. European Union 2013). In this article, the concept of mobility refers to people's movements outdoors, in terms of transportation to access desired places, activities, and people (i.e., destination-dependent) or simply to move around (i.e., destination-independent). Both perspectives (i.e., destination-dependent and -independent) can be important for a person's health and wellbeing (cf. Mollenkopf et al. 2004). The subjective meaning of getting out and about includes the psychological and social benefits of mobility as a personal resource and the ability to take part in society. Metz (2000) and Kaufmann et al. (2004) have also identified another dimension of mobility: The potential to travel, which is sometimes discussed in terms of motility. In this article, we refer to mobility experiences of accessibility, independence, safety, and wellbeing among younger and older people; the concepts are further developed here below.

In modern societies, mobility is often considered a prerequisite for citizens to have independence and participate in activities, access services, and form social relations. In this context, the concepts of independence and wellbeing appear closely connected to meeting personal needs, such as earning 
a living (i.e., benefitting from education and work), to the right to choose how, when, and where to meet these needs, and to building self-confidence (cf. Eid and Larsen 2008). Independence in children and younger people is often described as a maturing process leading to adulthood (cf. Holdsworth and Morgan 2005), and their mobility can be a means of expressing independence, or interdependence when children rely on adults to meet their mobility needs (Nansen et al. 2015). Research on older people finds that impaired mobility and physical inactivity are risk factors for further disability, leading to dependence and even death (cf. Hirvensalo et al. 2015). At the same time, the independence ideal has been found to be stigmatising among disabled older people who need to relocate to a residential home. These older people regarded their ordinary home as a source of independence and an expression of their identity, blaming their bodies for failing to meet the preconditions for 'normalcy' (Söderberg et al. 2013, p. 398). While loss of mobility as physical movement can and often does affect older people's sense of wellbeing adversely, this is not necessarily so; other mobilities (e.g., communication media), can compensate for the loss of mobility in physical space. Finally, wellbeing is also enhanced through mobility as movement in physical space because the latter enables independence or subjectively experienced autonomy, as well as inter-dependence in the sense of relatively equal and reciprocal social relations with other people (Ziegler and Schwanen 2011).

The concepts of 'access' and 'accessibility' are together with 'safety' common concepts for research on mobility and for planning on, e.g., traffic environments, vehicles, and areas for pedestrians. Safe mobility is seen as essential to people's actions, community life, and for health and well-being. It has been stated that when safe driving is no longer possible for older adults, safe and practicable alternative transportation must be available (Oxley and Whelan 2008; Tournier et al. 2016). Fear of crime may be a barrier to public transport use, and research suggests that feelings of anxiety and discomfort associated with travelling with people you do not know are an important factor leading to negative feelings of personal safety on public transport (Currie et al. 2013).

In transport and mobility research and planning, accessibility is often defined and employed as an objective and measurable concept, used in connection with the physical environment. As defined by Iwarsson and Ståhl (2003) and developed by Wennberg (2009), accessibility is a relationship between personal and environmental components and is related to societal norms and legislations. Even after physical barriers are removed, transport accessibility often remains a problem; it is a complex issue, touching on components such as the affordability of public transport, information devices, and understanding how to use them (cf. Lucas 2004; Smith 2009). In this article, the concepts of mobility and accessibility are seen in relation to practice, i.e., citizens' everyday life activities. The practice of everyday mobility involves the moving human body in the transport system (which is observable) as well as one's desires, abilities, and resources, which are only partly observable and may be investigated indirectly by observing their manifestations.

The article takes up the idea that social practice is connected to infrastructure across space and time (Shove et al. 2015). In taking this approach, we work with the proposition that the forms of mobility in a society are dependent on citizens' everyday practices and on the structure of the cities, landscapes, etc. Automobility, for example, can be understood as the outcome of interconnected patterns of social practices, such as working, going to school, shopping, and visiting friends and family. Following Shove et al. (2015), we also acknowledge that social practices are partly constituted by and embedded in material arrangements that cannot be controlled by individual transport users.

\subsection{Contexts}

The Swedish Public Transport Association (2018) decided in the year of 2008 to double the market share of public transport in Sweden by 2020; the target was recently moved forward to 2030 . The transport planning of cities and regions will accordingly concentrate on reducing car commuting and increasing public transport use. The Association also said that reducing car dependency among both younger and older people would be good for the economy and that succeeding in this would require new attitudes and behaviours. The idea of reduction of car dependency and increase of public 
transport is the context for the present analysis. Today in Sweden, about 85 percent of the citizens regularly travel by car, while about 50 percent regularly travel by public transport (regularly refers to travelling at least once a month). According to the annual report (The Swedish Public Transport Association 2017): 9\% of regular users of public transport are 15-19 years; 14\% are 20-25 years; 33\% are 26-44 years; 25\% are 45-64 years; and 19\% are 65-85 years. Younger people travel more often with public transport compared to those in older age groups. Women travel more often by public transport than men, while men more often travel by car than women. This is partly because men have a driving license and access to a car to a greater extent. A characteristic public transport passenger is aged 15-44, a student, and a woman. Among people aged 15-19, a high proportion of public transport use are school trips. People aged 15-25 years travel to a greater extent than other age groups with the combination of walking and public transport. The proportion of those who use public transport as the main means of transport decreases with increasing age, and those who seldom travel by public transport are found in the age group 65-85 years.

Data, collected from 2009 to 2017, originate from two focus group studies conducted on different occasions within this period but using similar approaches and arrangements. Focus group interviews have several advantages over one-to-one interviews. First, they provide a method of collecting data from strategic groups of people in a more 'naturalistic' way (Wilkinson 2004, p. 180) than interviews, since the participants stay closer to everyday language. Second, they typically involve communicative processes such as agreement, disagreement, development of arguments, and expression of thoughts, processes that researchers' questions might otherwise overlook. Third, it is a cost-effective way of collecting data, because group interviews take less time than individual interviews, though this advantage often depends on whether participants can be recruited effectively via existing groups (e.g., students at a secondary school or residents in housing for older people).

The data used here were gathered on two different occasions because the studies were financed through two different research calls; so far, we have not received funding to design and perform a comprehensive examination of teenagers' and retired people's mobility in a single research project. This topic is interesting because transport networks should ensure access to key public services, such as education and healthcare, and because the lives of citizens and groups of citizens may be affected differently by the transition to a more environmentally friendly transport system. That is why it is germane to link these previous studies and interpret them jointly through the lens of everyday mobility practices.

\subsection{Younger People}

Research into children's mobility assumes that independent mobility is important for children's development, health, and wellbeing; however, a decline in children's independent mobility has occurred in the last thirty years (cf. Joelsson 2019). Younger people are often dependent on adults to meet their mobility needs. They must travel to school five days a week but have more limited options than adult commuters and may only have access to school buses or commuter passes for public transport for a limited part of the day. Research has found that children are increasingly driven by car to and from school and various recreational activities (Barker 2003; Mikkelsen and Christensen 2009). Independent mobility is considered important for physical and mental health and walking and bicycling have been emphasised for health purposes. Further, children's traffic safety is important, and children tend to be hindered in their mobility due to the traffic density and limited space for bicycling in many urban areas (cf. Joelsson 2019; Kyttä et al. 2015).

Jones et al. (2012) argued that the distinction between active and passive transport should be reconsidered, assuming that public transport always involves some sort of 'active' travel, i.e., walking or bicycling, and they advocate a policy of free bus tickets for teenagers, encouraging them to use public transport independently of parents and other adults. Other studies show that urban life itself may impede children's access to public space, recreation, and places for social life outside the family (Chaudhury et al. 2017). Space for walking and bicycling has decreased in favour of motorised 
transport, often inconveniencing people who lack driving licenses or access to a car. The concept of independent safe mobility encompasses both unaccompanied child travel and travel with peers. Barker (2003) noted the paradox that parents driving their children (for safety reasons) unwittingly create extra traffic, worsening the problem and reinforcing traffic as a barrier to other children's mobility. Nansen et al. (2015) suggested that children's everyday mobility is defined and constituted by interdependencies of relationships and materials. Children's mobility can be connected to and constrained by relationships with people across generations, places, times, etc.: 'The interdependencies of child mobility are negotiated through: transitions over time, technology mediation, travel on particular routes, and by routines of family and social life' (Nansen et al. 2015, p. 470; cf. Badland et al. 2011; Currie et al. 2013; Skelton 2010).

Throughout the research literature, we observe various discourses on mobility for older and younger people. These partially overlapping discourses treat mobility as a resource promoting healthy active lives and increasing the wellbeing of individuals in both groups. On closer examination, the discourse of transport mobility among older people tends to concentrate on either car driving or accessible public transport, and on the need to stay active and independent as long as possible. By contrast, the discourse of transport mobility among younger people emphasises moving away from dependence and achieving independence. In this literature on younger people, 'accessible transport' tends to stand for transport modes that younger people can use by themselves to avoid being dependent on parents or other adults. Children's independent mobility is often framed primarily as a physical health or 'active travel' issue. There has been a demand for more child-centred conceptualisation of independent mobility (Mikkelsen and Christensen 2009). A study from London pointed out that travelling without adults does not necessarily mean travelling alone. When free public transport was introduced, e.g., children aged 16+ get free and discounted travel, it increased the capabilities of groups of young people to travel together and to reach places outside the neighbourhood. One participant commented that travelling on public transport could be more inclusive than staying at home because it could involve more people. Affordable bus rides gave accessibility for freedoms to shape daily mobility, including 'when, where and with whom they travelled' (Goodman et al. 2014, p. 288).

\subsection{Older People}

In the past few decades, research into older people's everyday mobility has coalesced around the concepts of accessibility, wellbeing, and independence. Much previous research into mobility and accessibility seems to be concerned with the physical environment and the ability to reach certain places by various transportation modes. In this sense discourses on younger and older people are similar: to reach places outside the neighbourhood. The concept of accessibility for older and disabled people has become central to modern policy (cf. Alsnih and Hensher 2003; Metz 2000; Ståhl and Ivarsson 2007; Hallgrimsdottir et al. 2016), and today, mobility is a notable concern in the gerontological discourse of wellbeing and independence (understood as the capacity to move through physical space and enjoy independent living). Mobility and independence are considered important components of wellbeing, for example: 'mobility allows people to engage in everyday activities outside the home that are meaningful and enhance wellbeing, whilst independent living gives older people control over the times and places in which activities are carried out' (Schwanen and Ziegler 2011, p. 720; cf. Banister and Bowling 2004; Schwanen et al. 2012). The fact that older people are ageing in place in many Western societies has increased and will continue to increase the need for mobility solutions in later life. However, the promotion of wellbeing and out-of-home mobility for older people is to some extent in tension with the challenges of introducing a more sustainable transport system and reducing $\mathrm{CO}_{2}$ emissions (Banister 2008). Often cited is the longitudinal study of four European cities (Marottoli et al. 1997, 2000) that concluded that driving cessation was among the strongest predictors of increased depressive symptoms in older people, and that measures to enhance the mobility of older 
people may help them to live independently in their own homes for longer, which generally both satisfies individual desires and reduces the cost of healthcare to society (cf. Metz 1999).

In recent decades, transport-related gerontological research has also notably focused on traffic safety for older people. From a traffic safety perspective, it has been argued that one should prolong driving among older people and postpone driving cessation as long as possible (Hakamies-Blomqvist et al. 2004; Siren and Hakamies-Blomqvist 2004; Marottoli et al. 1997; Oxley et al. 2010; Rosenbloom 1988, 2004; Rosenbloom and Herbel 2009). Previous research has also identified a gender difference between older men and women when it comes to mobility options. However, these differences have tended to decrease, and older women today travel more and are more often car drivers than were previous generations (Hjorthol et al. 2010; Rosenbloom and Herbel 2009). It has been stated that older women (aged 65+ years) use public transport more than men of the same age. Rosenbloom (2004) found that almost nine out of ten public transport users aged 65 years or older were women, and although the exact figures differ between countries and regions, this gender difference is a general tendency in most modern societies. Although public transport use increases with age, cars are still of great importance for older people in many geographical contexts (Mollenkopf et al. 2002, 2011; cf. Berg et al. 2015).

\subsection{Younger and Older People}

Most research on public transport use and experience has so far tended to consider either younger or older people, and there are few qualitative studies of public transport that consider both age groups. One such study examines concessionary public transport and wellbeing in London, UK. It draws on qualitative data about two groups typically considered at risk of transport exclusion: Younger people aged $12-18$ years $(n=118)$ and older people aged $60+$ years $(n=46)$. The data were collected in London, UK, where younger people and older citizens were entitled to concessionary bus travel for the duration of the study. The results indicated high confidence among both groups regarding their entitlement to travel for free, seen as reflecting their social worth, particularly for older citizens. One main conclusion was that providing concessionary transport entitlement helped to counter feelings of social exclusion by enhancing recipients' sense of belonging to the city and to a 'community' (Jones et al. 2013). Another study based on twelve face-to-face interviews and six focus groups in the UK among car drivers and public transport users demonstrated that people seem to have a default source of travel information that they use for most trips. They do not tend to travel by public transport without consulting any public transport information, unless there are no time constraints, the service runs frequently, or the journey is local. Differences were found between younger and older participants; for example, the Internet is the usual default travel information source for people under age 60. Older people prefer face-to-face contact by visiting their local public transport station, whereas younger people prefer to look up the information for themselves online (Faraq and Lyons 2008).

An Australian study showed that public transport convenience was very important to most participants irrespective of age, and researchers concluded that transport availability and reliability must be given a higher priority to promote public transport. This study was based on 301 participants in 43 focus group discussions, 31 attended by older participants (aged 60+ years) and 12 by younger participants (aged 18-59 years). Features of transport convenience cited by both younger and older adults included: Appropriate timetables, scheduling, and routes; convenient bus stop locations; bus connections with other modes of transport; flexible and low-cost ticketing systems; prior knowledge; and provision of smaller buses. Older adults appreciated friendly and helpful drivers, easy entry and exit, and useable information as facilitating the use of buses. By contrast, younger adults prioritised information at bus stops, availability of bus services, and availability of parking near bus stops. Older participants emphasised direct services to specific destinations, such as shopping centres, unlike younger adults, who emphasised routes between suburbs, direct services, and reduced journey time. The types of destinations prioritised by older people (e.g., hospitals and nursing homes) reflected activities particularly relevant to this age group. Researchers have recommended that scheduled 
bus services be linked to key facilities in the community as an important strategy to enhance the community participation of both younger and older adults (Broome et al. 2010).

\section{Materials and Methods}

The empirical material for this article is based on focus group interviews conducted from 2009 to 2017. The material used here comes from sub-studies included in two large and separate projects.

In the study, 'Mobile Age: The Impact of Everyday Mobility for Elderly People's Welfare and Wellbeing', retired people aged 60 years and above were interviewed in 10 focus groups (4-7 people per group, equal numbers of men and women) from two geographic areas: Ödeshög (a small municipality) and Stockholm (Sweden's capital). In total, 51 people participated in this study, which took place from 2009 to 2010. The interviewees were recruited from three age groups in the two geographic areas: 60-70, 70-79, and 80+ years old. The youngest person was 63 and the oldest was 97 years old.

In the study, 'Public Transport's Role and Place in Everyday Mobility-Today and in the Future', schoolchildren aged 14-16 years were interviewed in 12 focus groups (10-12 people per group) in three cities: Uddevalla in the west, Malmö in the south, and Stockholm. In total, 166 teenagers (approximately as many women as men) participated in the study, which took place from 2016 to 2017. The interviewees were recruited from three secondary schools.

The focus group discussions were moderated by a researcher, and in some of them, an assistant researcher took notes. Questions were thematic, and participants were invited to develop their own questions and ideas during the discussion. All focus groups were audio recorded with participant permission (cf. Codex 2018). The analysis for this article was based on focus group transcriptions, field notes from the two projects, and the results of conference presentations (not previously published).

The recruitment methods were somewhat similar in both projects: We contacted potential participants via study and leisure groups and secondary schools in a total of four municipalities, both larger and smaller. In the 'Mobile Age' project, which studied older people's mobility in urban and rural areas, the capitals of three Nordic countries (i.e., Denmark, Norway, and Sweden) were chosen in combination with one smaller, rural municipality in each country. The youth study started in a small city and then expanded to a large and a medium-sized city. The cities are briefly described below:

- Ödeshög is a small, rural municipality with about 5500 residents located in Central Southern Sweden. Other cities (both small and large) are within commuting distance; it has no train service but quite a few bus routes, mostly designed for travel to school or major workplaces.

- Uddevalla is a small city in Western Sweden with about 55,000 residents. It is within commuting distance of the city of Gothenburg with about 570,000 residents in the municipality and about 1 million in the metropolitan area. It has a good supply of public transport.

- Malmö, a medium-sized city in the south, is the third largest city in Sweden with about 330,000 residents in the city proper and 700,000 in the metropolitan area. It also has a good supply of public transport.

- Stockholm, Sweden's capital, has about 900,000 residents in the city proper and 2 million in the surrounding metropolitan area. Stockholm is located on the east coast and is served by an extensive public transport network.

\section{Results}

This section brings together results of the two contributing studies. The analysis has been guided by the concepts of accessibility, independence, safety, and wellbeing, which were outlined in Section 2, and by the research questions presented in Section 1. Quotations from the focus groups were chosen to illustrate recurrent patterns. 


\subsection{Younger People}

The focus group study of younger people began in 2016 as part of a Living Lab study in Uddevalla (cf. Book et al. 2019), where we found that teenagers were very negative towards public transport and especially the bus service. Researchers also discovered during travel observations that schoolchildren were de-prioritised in bus services in favour of adult commuters. Teenagers described themselves as being treated as 'second-class' public transport users. This knowledge became the starting point of an extended study of teenagers in three Swedish cities. We chose three cities of different sizes with varied public transport systems allowing travel at different times of day. Despite a fairly good supply of public transport, younger people's preferences for and stories about public transport differed between cities, which were considered in terms of their density and the local status of their transport systems. There were no substantial differences between younger women and men participants in this study. Below follow illustrative quotations from the focus groups.

In Uddevalla, we found strong resistance to public transport use, and the car was said to be a natural first choice: 'The car is easiest, the car is the only transport mode that works where I live.' 'The moped is best because I can go everywhere at any time-when I grow up I will get a car.' 'I don't like public transport!'

In Stockholm, where the metro and bus networks are extensive, the opposite was evident, i.e., public transport, combined with walking, was the first choice: 'The metro is fast, and you can usually get around Stockholm. It is environmentally friendly and quite efficient, and it runs often and is not delayed as often as buses.' 'I prefer walking-it is pleasant to move around and good for the environment.'

In Malmö, multimobility characterised by a varied mix of bicycles, buses, and cars was prevalent: 'The bicycle is best, especially when it's warm, but I take the bus in autumn and winter.' 'It [i.e., the bicycle] is fast-I can go wherever I want, and it costs less.' 'The bus is a good environmental choice. It takes me everywhere and I don't have to bother any adult to drive me.'

The results also indicated that even though the youths were de-prioritised relative to adult travellers in the public transport system (as was found to be the case in Uddevalla), their quality and punctuality expectations were as high as those of other travellers, and they also expected a clean and pleasant public transport environment with, for example, clean seats and fresh air in the buses, and ample shelters, benches, etc., near the bus stops. Participants in the focus groups defined well-functioning public transport relative to the car, for example, in terms of 'when you want to take public transport instead of the car' and 'freedom to travel wherever you want whenever you want'. Most said that they felt safe and secure on public transport most of the time. However, some described not feeling safe due to the presence of other travellers, especially late in the evening when threatening people loiter around metro stations and bus stops: 'When I'm travelling alone by metro, I try to avoid threatening people by joining groups of adults or families with children' (student, Stockholm). Further, disturbing incidents such as delays or cancelled buses or trains can affect one's personal integrity, since you have to stand and wait (sometimes in an unsheltered place beside the road) for a longer time than you have planned and feeling anxious with people you do not know. Young women expressed how they had developed strategies to increase their safety when travelling alone in the late evenings. For example, they looked around to find a family or an adult couple and then stayed close to them. Another safety issue is the high traffic density in the city. Few younger people in Stockholm rode their bicycles in the city, cycling only in the countryside or suburban areas, and just one of the 55 participating students in Stockholm said he owned a moped and liked to ride it when he went out in the evenings. The teenagers' stories illustrated how younger people could be discriminated against just because of their age. For example, some of them referred to rude ticket inspectors: 'Sometimes they treat us as potential troublemakers. They can be very unpleasant-they suspect that you want to cheat' (student, Uddevalla).

Future mobility was also a concern: 'Within ten years I will have a car', and 'It's convenient and flexible to take a car or moped,' said students in Uddevalla. However, a few students in Uddevalla said 
they would like to continue to use public transport: 'I think it's pleasant and I will continue to use it'; 'It depends on what I will do and where I will live'; and 'Electric buses will probably be common-they already exist today.' When we asked what might influence their travel in the near future: 'Plan B when it [i.e., public transport] does not work—which often seems to be the case' (student, Malmö); 'Access to extra buses if the ordinary buses are full, and if there is a traffic jam or some big event. For example, if there is a big match or any other big event, then public transport needs to be adjusted' (student, Uddevalla); 'Good air conditioning, which is not the case in the buses today' (student, Uddevalla); and 'More 'Superbuses" (student, Malmö). (Superbus is a new concept, i.e., well-equipped modern buses that were running on a few routes in Malmö at the time of the study). Another wish was better organisation of bus timetables to fit leisure activities, and more convenient bus stop locations: 'There isn't even a bus stop near the arena, where I play football' (student, Uddevalla). The participants lived in urban, suburban or rural areas; and for some of them, the travel card for leisure trips was a great expense. Most of the participants travelled by school buses or had access to ordinary public transport (e.g., city buses, metro) for travelling to school on weekdays, and in all three cities, the teenagers expressed wishes for access to free or cheap public transport on weekends and holidays.

The results of the focus groups among the younger people indicate that younger people constitute a heterogeneous group with many different experiences. Interestingly, this heterogeneity expresses itself in various ways in practice and in relation to the structure of the place (cf. Levin et al. 2019). The experiences of youths being de-prioritised in the public transport system in Uddevalla were unexpected. Only in Stockholm, with its extensive public transport system, did secondary school students express that they feel treated as real public transport customers. From the younger people's perspective, the public transport system displayed relatively low trust in them in the small city of Uddevalla, and relatively high trust in the city of Stockholm, while the level of trust was intermediate in the medium-sized city of Malmö. Students expressed confidence about moving rather freely by the public transport system in Stockholm and Malmö, and by bicycle in Malmö. Independence can be linked to different transport modes in the different cities: Metro, buses, and walking in Stockholm; bicycles and buses (and cars to some extent) in Malmö; and mopeds and cars (when they get older) in Uddevalla. The financial situation was not the main topic in this study; however, it was reflected in the participants' wish for free or cheaper transport. Free public transport could remove financial barriers, increase young people's independence (cf. Goodman et al. 2014), and raise the likelihood that they will continue to use public transport for their everyday mobility, even after they have reached the age to get a driving license (18 years).

\subsection{Older People}

The original design of the focus group study of older people was based on previous findings from within the Mobile Age project (e.g., the recognition that retired people today travel much more than previous generations), and on the assumption that wellbeing in later life relates to being able to get out and about every day (Hjorthol et al. 2010). Notably, the focus group interviews told stories about life-long mobility, and the participants described their daily lives in relation to geography and their current mobility opportunities. Mobility barriers were recognised in their stories, as were strategies, for example, for combining public transport with other transport modes, such as bicycling and walking. For example, one might walk in one direction, usually from home, and then take the bus back-a strategy addressing both exercise and the fact that the buses run quite infrequently at times when older people want to be out of the home.

They also stressed the importance of going out, meeting people, moving around in different environments, and, in particular, the health benefits of 'going out' every day (cf. Berg et al. 2014).

'I want to go out every day, if nothing else, to do some shopping,' said an 80-year-old woman, expressing the value of daily walking and shopping as routine activities. She wanted to choose what to buy at the grocery store and bakery, and said it was a way to be independent, versus if she had her groceries delivered to the door. 
However, sometimes older people might choose to stay at home, according to one woman aged 80+ years: 'You see, I do not have to travel every day each week-I can choose another day if the weather is bad or if I feel tired.'

Some of the restrictions (cf. Berg 2016) mentioned in the participants' stories are self-imposed (e.g., staying home on a rainy day), while others cannot be ameliorated by the individual, for example, a distant bus stop, steep stairs at transport depots and interchanges, unsynchronised timetables, and buses at times that do not fit older people's daily activity patterns. The latter perceptions (unsynchronised timetables, and lack of bus service) correlate to perceptions from the teenagers' view of available public transport to their leisure activities (e.g., the lack of bus service to the sports arena). Aside from deficiencies in public transport, restrictions can also arise from poor sidewalk maintenance and from cycle paths or footpaths that end at a different level relative to the next accessible area (cf. Wennberg 2009). When even one link in the whole chain of movement in the transport environment is not accessible, problems may occur and after that, some may avoid taking part in planned activities. The oldest respondents particularly appreciated different parts of the journey being connected in space and time, as even one seemingly minor barrier on the way could spoil the whole journey.

Our study found that more women than men lived alone when they reached an advanced age (80+ years), and that most of the oldest women had no driving license and/or no car. We held a focus group of women aged $80+$ years living in special housing in the small municipality; they used roller walkers, and some of them could manage the short distance to a small shop in the neighbourhood and to the library. The talk shows that it is not just a matter of accessible and safe mobility but practice (cf. Women 1) and resources (cf. Woman 3):

Moderator: What if you want to go, go to a restaurant and cafe and do such things—can you do it when you live here? Can you get away with it?

W1: We could do that, but we do not.

W2: No, it cannot be.

W3: No, we cannot afford to go to a restaurant-it costs a lot to live here.

The young-old (i.e., newly retired) and the medium-old people were frequent car drivers. Some of them could also be categorised as multimodal travellers, shifting between different transport modes, and this pattern was more common among women than men. Men more often said that they preferred their own cars and found no reason to give them up before they were forced to by poor health or advanced age. One man (aged 80+ years) said: 'For those who have had a car for 40-50 years ... when it's gone, then much of their freedom is lost, very much.' The interviewees pointed out that car dependency is likely to increase with age, which is undoubtedly a dilemma since the ability to drive concurrently decreases. The interviewees living in rural places spoke of their cars as 'absolutely necessary', while those in the capital spoke of driving as more of a lifestyle and convenience option for travelling outside the city and reaching a summer house. This study confirmed a finding of other studies, namely, that younger pensioners travel more than the oldest. Surprisingly, the oldest people (aged $80+$ years) in the city of Stockholm travelled frequently by public transport, by metro, trams, and buses. At the same time, the transportation needs of the oldest in the small municipality were notably difficult to meet. Some of them had access to a special transport service, which had to be booked two hours before the journey, and if they wanted to travel longer distances, they had to make a booking one day in advance. When it comes to the special transport service (STS), which are parts of the public transport system in Sweden, we heard as many good as bad stories. STS is a community-paid service for the disabled and the older people who cannot use ordinary public transport and it is often operated by private taxi or bus companies on behalf of local governments. Passengers who used both ordinary public transport and STS were often confused by the different regulations and ways of paying the fare, and the booking system itself could be a barrier to travelling. One group of people entitled to STS found it difficult to use any other form of public transport. STS and other fixed-route services for older 
and disabled people were often recognised as modes of last resort, which a man aged 80+ years in Stockholm expressed as follows: 'Travel service makes you lose some of your personal freedom.'

There are quite many studies from the past decades about older people's mobility, especially on older people's automobility. Retired people today are travelling more than generations before (cf. Hjorthol et al. 2010), and they have been part of a developing practice of auto-mobility, and it is certainly visible in the interviews. There occur to some extent similar differences between the small and the big city compared to the study with younger people, which are related to the participants' confidence with public transport in the capital and the car preference in the municipality of Ödeshög. However, the old age study was not designed in exactly the same way as the study of secondary school students, and we cannot draw too large comparative results between these two studies. The importance of the results of the focus groups among older people is, first, that qualitative studies of this kind, examining practice and experience, will improve our knowledge of the heterogeneity of ageing people, complementing travel surveys and cohort analysis. Second, such studies identify pertinent alternative categories (besides chronological age), for example, specific rural and urban living circumstances or gendered ageing with variations in financial and other resources, driver licensing, car access, and access to public transport solutions. Third, such studies build awareness of the seemingly small barriers that might crucially affect older people's ability to maintain safe mobility, independence, and wellbeing. The results stress that the idea of continued car driving among ageing people should be reconsidered, both because car ownership varies among groups of ageing people (e.g., gendered differences), which is notable in rural areas, and because of the politics of sustainable mobility (cf. Shergold and Parkhurst 2010).

\section{Discussion}

This study took its starting point in mobility research on two groups, i.e., older and younger people, whose practices have hitherto been at the margins of public transport planning processes. People are considered constructing mobility in everyday life. Mobility is considered dependent on citizens' everyday practices and on the structure of cities and landscapes. It can be understood as the outcome of interconnected patterns of social practices, for example, going to work or school, visiting friends and family, shopping, and recreation, but also as the outcome of the structure of residential areas, the locations of workplaces, schools, and leisure activities, and the institutions and organising practices of society (cf. Shove et al. 2015). In Section 2, we took a short look at the research field of mobility among younger and older people. Then, the recurrent concepts of accessibility, independence, safety, and wellbeing were used to provide guidance when interpreting the empirical material. Transport needs and accessibility may vary depending on contexts, i.e., where and how we live and the various resources available to different groups of citizens. At the same time, there are divergent views of what changes will entail for different groups of citizens amid the current transition from automobility to other transport modes (e.g., public transport, bicycling, and walking), and teenagers and retired people can be considered outside the usual and dominant flow of passengers and their daily commuting practice.

The study considered three old-age groups, i.e., the young-old aged 60-70 years, the medium-old aged 70-79 years, and the old-old aged 80+ years, and captured variations in the experiences, problems/opportunities, and limitations experienced by these groups in their everyday mobility. We emphasised variations among subgroups (e.g., the old-old, medium-old, and young-old), life in rural versus urban areas, and gender aspects, all of which we believe merit consideration when trying to understand how and why people plan their everyday journeys. In the future, certain matters will have to be considered in relation to the practices of older people. One such matter is the risk of isolation when public transport does not work, or when the barriers to use are too high or too numerous-even one seemingly small obstacle may spoil the whole journey or result in hesitant behaviour that results in decreased out-of-home activities. The tendency towards car dependency among older people will be crucial for social reasons and will challenge efforts to reduce negative environmental effects. Part 
of the problem concerns ideas of how to maintain and extend the independence of retired people. The policy of encouraging older people to drive is not environmentally sustainable, though driving protects them from severe injury, and mobility challenges are especially serious for those living in rural places with poor public transport service or no close relatives or friends (cf. Shergold and Parkhurst 2010). However, wellbeing can also be found in freedom from routine mobility, which was obvious in some focus groups when people said that they chose to stay at home if they felt tired or the weather was bad; in such cases, daily exercise requirements need to be considered.

Similarly, the concept of independence appeared important in discourse among the secondary school students (aged 14-16 years) interviewed in the three cities. Younger participants in the focus groups defined well-functioning public transport in relation to the car, for example, in terms of 'when you want to take public transport instead of the car', and 'freedom to travel wherever you want whenever you want'. The study shows that both the car and public transport can stand for social freedom and independence, differently in different urban contexts. Many of the teenagers displayed high commitment to the metro and bus services, especially in the two biggest cities, and in all three cities, they appreciated convenience and safety. Walking (in Stockholm) and cycling (in Malmö) were much appreciated, illustrating that, when possible, the teenagers chose not to use motor vehicles to meet their everyday mobility needs. Very few younger people in Stockholm classified themselves as cyclists (and those who did, rode their bicycles only in the countryside or suburban areas), mentioning that nobody dared ride their bicycles in the heavy traffic of the city. Only one person said that he liked to travel by moped.

The preferred status of the car seems to have been replaced by that of multimobility in the production and reproduction of everyday life for both younger and older people in Stockholm, and for younger people in Malmö. While the car (and the moped for younger people) represent comfort and freedom in the smaller cities of Uddevalla and Ödeshög. Despite the rather hopeful results (at least regarding the younger people's travels in a medium-sized and a big city), there is no definite link between younger people's daily travels, their thoughts about future transport choices, and how they will eventually meet their future mobility needs (this was further discussed by Levin et al. 2019). Instead, we want to emphasise their role as members of society today, in this case, as urban residents and 'customers' of metro, train, and bus services. Few older and none of the younger people participating in these focus groups had been involved in the planning process for new transport infrastructure development or for transport system maintenance. It seems that planning processes seldom seek to involve older or younger people in consultation.

Power and influence vary among citizens, and it must be emphasised that the routinisation of automobility, public transport use, bicycling, walking, etc., emerges through the intersection of various infrastructural arrangements that are integral to the simultaneous conduct of multiple practices (cf. Shove et al. 2012; Shove et al. 2015). The notions of diversity among citizens and diversity within groups of citizens are quite important in relation to mobility practice. This study exemplifies with a group of school teenagers and a group of older people (including young-old, middle-old, and old-old) and displays that practice and resources are connected to different environmental contexts. The transport sector's impact on climate change therefore depends not only on individuals' everyday mobility behaviours and choices, and not only on changing transport users' attitudes and behaviours, but also entails changing the practices of organisations and institutions, and the redesign of urban space as well as the renewal of the connections between rural and urban areas. In societal efforts to promote sustainable mobility, it becomes evident that the everyday lives and everyday activities/practices of citizens merit study in relation to the multiple practices of, for example, institutions, municipalities, and transport providers. More work is needed to explore how practices are varied as different groups go about meeting their various needs.

Funding: This article received no extra funding. The research project 'Mobile Age: The Impact of Everyday Mobility for Elderly People's Welfare and Wellbeing' was funded by NFR, the Research Council of Norway, grant 
number 187780/S2 and the project 'Public Transport's Role and Place in Everyday Mobility-Today and in the future' was funded by K2, The Swedish Knowledge Centre for Public Transport, grant 2015/FOU5.

Acknowledgments: The Mobile Age study was accomplished in collaboration with Randi Hjorthol, TOI Oslo, Pål Ulleberg, Oslo University, Anu siren, DTU Denmark, and Jessica Berg, VTI Sweden. The study of Public Transport's Role and Place in Everyday Mobility was accomplished in collaboration with Karin Book, Malmö University, Åse Svensson, Lund University, and Ann-Charlotte Gilboa Runnvik, Mind Your Way, Stockholm.

Conflicts of Interest: The author declares no conflict of interest. The funders had no role in the design of the study; in the collection, analyses, or interpretation of data; in the writing of the manuscript, or in the decision to publish the results.

\section{References}

Alsnih, Rahaf, and David A. Hensher. 2003. The mobility and accessibility expectations of seniors in an aging population. Transportation Research Part A: Policy and Practice 37: 903-16. [CrossRef]

Badland, Hannah M., Melody Oliver, Mitch J. Duncan, and Peter Schantz. 2011. Measuring children's independent mobility: Comparing objective and self-report approaches. Children's Geographies 9: 263-71. [CrossRef]

Banister, David. 2008. The sustainable transport paradigm. Transport Policy 15: 73-80. [CrossRef]

Banister, David, and Ann Bowling. 2004. Quality of life for the elderly: The transport dimension. Transport Policy 11: 105-15. [CrossRef]

Barker, John. 2003. Passengers or political actors? Children's participation in transport policy and the micro political geographies of the family. Space and Polity 7: 135-51. [CrossRef]

Berg, Jessica. 2016. Everyday Mobility and Travel Activities during the First Years of Retirement. Ph.D. dissertation, NISAL, National Studies of Ageing and Later Life, Department of Social and Welfare Studies, Linköping University, Linköping, Sweden.

Berg, Jessica, Lena Levin, Marianne Abramsson, and Jan-Erik Hagberg. 2014. Mobility in the transition to retirement-The intertwining of transportation and everyday projects. Journal of Transport Geography 38: 48-54. [CrossRef]

Berg, Jessica, Lena Levin, Marianne Abramsson, and Jan-Erik Hagberg. 2015. 'I want complete freedom': Car use and everyday mobility among the newly retired. European Transport Research Review 7: 31. [CrossRef]

Book, Karin, Lena Levin, and Ann-Charlotte Gilboa Runnvik. 2019. Collaboration around public transport in a geographically defined but institutionally undefined setting. Forthcoming article.

Broome, Kieran, Emily Nalder, Linda Worrall, and Duncan Boldy. 2010. Age-friendly buses? A comparison of reported barriers and facilitators to bus use for younger and older adults. Australasian Journal on Ageing 29: 33-38. [CrossRef]

Chaudhury, Moushumi, Erica Hinckson, Hannah M. Badland, and Melody Smith. 2017. Children's independence and affordances experienced in the context of public open spaces: A study of diverse inner-city and suburban neighbourhoods in Auckland, New Zealand. Children's Geographies 17: 49-63. [CrossRef]

Codex. 2018. Rules and Guidelines for Research: Informed Consent. Available online: http:/ /www.codex.vr.se/ en/manniska2.shtml (accessed on 1 December 2018).

Currie, Graham, Alexa Delbosc, and Sarah Mahmoud. 2013. Factors influencing young peoples' perceptions of personal safety on public transport. Journal of Public Transportation 16: 1-19. [CrossRef]

Eid, Michael, and Randy Larsen. 2008. The Science of Subjective Wellbeing. New York and London: The Guilford Press.

European Environment Agency. 2017. Green Choices: Policymakers, Investors and Consumers. Available online: https: / / www.eea.europa.eu/signals/articles / (accessed on 22 January 2019).

European Environment Agency. 2018. Towards Cleaner and Smarter Mobility. Available online: https://www.eea. europa.eu/signals/articles/ (accessed on 23 January 2019).

European Union. 2013. Free Movement of EU Citizens and Their Families. Available online: https:/ / ec.europa.eu (accessed on 1 February 2019).

Faraq, Sendy, and Glenn Lyons. 2008. What Affects Use of Pretrip Public Transport Information? Empirical Results of a Qualitative Study. Transport Research Record 2069: 85-92. [CrossRef] 
Goodman, Anna, Alasdair Jones, Helen Roberts, Rebecca Steinbach, and Judith Green. 2014. 'We can all just get on a bus and go': Rethinking independent iobility in the context of the universal provision of free bus travel to young Londoners. Mobilities 9: 275-93. [CrossRef]

Hakamies-Blomqvist, Liisa, Anu Siren, and Ragnhild Davidse. 2004. Older drivers-A review. VTI Report 497A. Hallgrimsdottir, Berglind, Hanna Wennberg, Helena Svensson, and Agneta Ståhl. 2016. Implementation of accessibility policy in municipal transport planning_Progression and regression in Sweden between 2004 and 2014. Transport Policy 49: 106-205. [CrossRef]

Hirvensalo, Mirja, Taina Rantanen, and Eino Heikkinen. 2015. Mobility Difficulties and Physical Activity as Predictors of Mortality and Loss of Independence in the Community-Living Older Population. Journal of the American Geriatrics Society 48: 493-98. [CrossRef]

Hjorthol, Randi, Lena Levin, and Anu Siren. 2010. Mobility in different generations of older persons: The development of daily travel in different cohorts in Denmark, Norway and Sweden. Journal of Transport Geography 18: 624-33. [CrossRef]

Holdsworth, Clare, and David Morgan. 2005. Transition in Context: Leaving home, Independence and Adulthood. Maidenhead: Open University Press.

Iwarsson, Susanne, and Agneta Ståhl. 2003. Accessibility, usability, and universal design: Positioning and definitions of concepts describing person-environment relationships. Disability and Rehabilitation 24: 231-42. [CrossRef]

Joelsson, Tanja. 2019. Hypermobile, Sustainable or Safe? Imagined Childhoods in the Neo-liberal Transport System. In Integrating Gender into Transport Planning. From One to Many Tracks. Edited by Christina Lindkvist Scholten and Tanja Joelsson. London: Palgrave Macmillan, pp. 221-48.

Jones, Alasdair, Rebecca Steinbach, Helen Roberts, Anna Goodman, and Judith Green. 2012. Rethinking passive transport: Bus fare exemptions and young people's wellbeing. Health \& Place 18: 605-12.

Jones, Alasdair, Anna Goodman, Helen Roberts, Rebecca Steinbach, and Judith Green. 2013. Entitlement to concessionary public transport and wellbeing: A qualitative study of young people and older citizens in London, UK. Social Science \& Medicine 91: 202-9.

Kaufmann, Vincent, Manfred M. Bergman, and Dominique Joye. 2004. Motility: Mobility as capital. International Journal of Urban and Regional Research 28: 745-56. [CrossRef]

Kyttä, Marketta, Jukka Hirvonen, Julie Rudner, Iiriis Pirjola, and Tiina Laatikainen. 2015. The last free-range children? Children's independent mobility in Finland in the 1990s and 2010s. Journal of Transport Geography 47: 1-12. [CrossRef]

Levin, Lena, Karin Book, and Ann-Charlotte Gilboa Runnvik. 2019. Future public transport users or active actors creating their own mobility? Young people and their perceptions of public transport in three different urban contexts (forthcoming article).

Lucas, Karen. 2004. Running on Empty. Transport, Social Exclusion and Environmental Justice. Bristol: Polity Press.

Marottoli, Richard A., Carlos F. Mendes de Leon, Thomas A. Glass, Christianna S. Williams, Leo M. Cooney Jr., Lisa F. Berkman, and Mary E. Tinetti. 1997. Driving cessation and increased depressive symptoms: Prospective evidence from the New Haven EPESE (Established Populations for Epidemiologic Studies of the Elderly). Journal of the American Geriatrics Society 45: 202-6. [CrossRef]

Marottoli, Richard, Carlos F. Mendes de Leon, Thomas A. Glass, Christianna S. Williams, Leo M. Cooney, and Lisa Berkman. 2000. Consequences of driving cessation: Decreased out-of-home activity levels. Journal of Gerontology: Social Sciences 55B: 334-40. [CrossRef]

Mattioli, Giulio. 2014. Where sustainable transport and social exclusion meet: Households without cars and car dependence in Great Britain. Journal of Environmental Policy and Planning 16: 379-400. [CrossRef]

Metz, David. 1999. Can the impact of ageing on health care costs be avoided? Journal of Health Services Research and Policy 4: 249-52. [CrossRef]

Metz, David. 2000. Mobility of older people and their quality of life. Transport Policy 7: 149-52. [CrossRef]

Mikkelsen, Miguel Romero, and Pia Christensen. 2009. Is Children's Independent Mobility Really Independent? A Study of Children's Mobility Combining Ethnography and GPS/Mobile Phone Technologie. Mobilities 4: 37-58. [CrossRef]

Mollenkopf, Heidrun, Fiorella Marcellini, Isto Ruoppila, Zsuzsa Szeman, Mart Tacken, Roman Kaspar, and Hans-Werner Wahl. 2002. The role of driving in maintaining mobility in later life: A European view. Gerontechnology 2: 231-50. [CrossRef] 
Mollenkopf, Heidrun, Fiorella Marcellini, Isto Ruoppila, and Mart Tacken. 2004. What does it mean to get old and more immobile-And what can be improved? In Ageing and Outdoor Mobility: A European Study. Edited by Heidrun Mollenkopf, Fiorella Marcellini, Isto Ruoppila and Mart Tacken. Amsterdam: IOS Press.

Mollenkopf, Heidrun, Anette Hieber, and Hans-Werner Wahl. 2011. Continuity and change in older adults' perception of out-of-home mobility over ten years: A qualitative-quantitative approach. Ageing E Society 31: 782-802.

Nansen, Bjorn, Lisa Gibbs, Colin MacDougall, Frank Vetere, Nicola Ross, and John McKendrick. 2015. Children's interdependent mobility: Compositions, collaborations and compromises. Children's Geographies 13: 467-81. [CrossRef]

Oxley, Jennifer, and Michelle Whelan. 2008. It Cannot be all about safety: The benefits of prolonged mobility. Traffic Injury Prevention 9: 367-78. [CrossRef]

Oxley, Jennifer, Jim Langfjord, and Judith Charlton. 2010. The safe mobility of older drivers: A challenge for urban road designers. Journal of Transport Geography 18: 642-48. [CrossRef]

Rosenbloom, Sandra. 1988. The Mobility Needs of the Elderly. Transportation in an Aging Society: Improving Mobility and Safety for Older Persons. Special Report 218. Washington: Transportation Research Board National Research Council, pp. 21-71.

Rosenbloom, Sandra. 2004. The mobility of the elderly: There's good news and bad news. In Transportation and an Aging Society. Edited by Transportation Research Board. Washington: National Academy Press, pp. 3-21.

Rosenbloom, Sandra, and Susan Herbel. 2009. The Safety and Mobility Patterns of Older Women: Do Current Patterns Foretell the Future? Public Works Management \& Policy 13: 338-53.

Schwanen, Tim, and Friederike Ziegler. 2011. Wellbeing, independence and mobility: An introduction. Ageing $\mathcal{E}$ Society 31: 719-33.

Schwanen, Tim, David Banister, and Ann Bowling. 2012. Independence and mobility in later life. Geoforum 43: 1313-22. [CrossRef]

Shergold, Ian, and Graham Parkhurst. 2010. Operationalising 'sustainable mobility': The case of transport policy for older citizens in rural areas. Journal of Transport Geography 18: 336-39. [CrossRef]

Shove, Elizabeth, Mika Pantzar, and Matt Watson. 2012. The Dynamics of Social Practice: Everyday Life and How It Changes. London: Sage.

Shove, Elizabeth, Matt Watson, and Nicole Spurling. 2015. Conceptualizing connections: Energy demand, infrastructures and social practices. European Journal of Social Theory 18: 274-87. [CrossRef]

Siren, Anu, and Liisa Hakamies-Blomqvist. 2004. Private car as the grand equaliser? Demographic factors and mobility in Finnish men and women 65+. Transportation Research Part F: Traffic Psychology and Behaviour 7: 107-18. [CrossRef]

Skelton, T. 2010. Young people's urban im/mobilities: Relationality and identity formation. Urban Studies 50: 467-83. [CrossRef]

Smith, Allison E. 2009. Ageing in Urban Neighbourhoods. Place Attachment and Social Exclusion. Bristol: Polity Press.

Söderberg, Markus, Agneta Ståhl, and Ulla Melin Emilsson. 2013. Independence as a stigmatizing value for older people considering relocation to a residential home. European Journal of Social Work 16: 391-406. [CrossRef]

Ståhl, Agneta, and Susanne Ivarsson. 2007. Accessibility, Safety and Security for Older Persons in the Local Outdoor Environment: The Demonstration Project 'Let's Go for a Walk'; Final Report. Kristianstad: Swedish Road Administration.

The Swedish Public Transport Association. 2017. Annual Report. Available online: https: / / www.svenskkollektivtrafik.se/globalassets/svenskkollektivtrafik/bilder/fakta/publikationer/ arsredovisning-2017 (accessed on 5 October 2018).

The Swedish Public Transport Association. 2018. Let's Double the Public Transport! Available online: https: / / www.svenskkollektivtrafik.se/partnersamverkan/in-english/ (accessed on 5 October 2018).

Tournier, Isabelle, Aurélie Dommes, and Viola Cavallo. 2016. Review of safety and mobility issues among older pedestrians. Accident Analysis and Prevention 91: 24-35. [CrossRef]

Wennberg, Hanna. 2009. Walking on Old Age: A Year-Round Perspective on Accessibility in the Outdoor Environment and Effects of Measures Taken. Bulletin 247. Ph.D. dissertation, Traffic \& Roads, Department of Technology and Society, Lund University, Lund, Sweden. 
Wilkinson, Sue. 2004. Focus group research. In Qualitative Research: Theory, Method and Practice. Edited by D. Silverman. London: Sage, pp. 177-99.

Ziegler, Friederike, and Tim Schwanen. 2011. 'I like to go out to be energised by different people': An exploratory analysis of mobility and wellbeing in later life. Ageing and Society 31: 758-81. [CrossRef] 